we must consider whether we are left claiming that the actual gender of those engaged in institutional politics is irrelevant to our concerns as feminists.

What is interesting in this development, is that if we distance ourselves from the assertion that there is a 'women's perspective' which we seek to introduce into politics, we are left simply asserting the importance of numerical equity: in other words, the anti-essentialist theorizing of poststructuralism takes us back to a liberal agenda. Unless, that is, we retain the materialist standpoint position that difference can be contingent rather than essential, but is none the less politically important for that.

In this context, Phillips clearly emphasizes that participatory forms of democratic politics have long been central to feminist practice. Throughout second-wave American feminism, the movement has been informed by democratic organization and practice - spontaneous gatherings and marches, diverse action groups, face-to-face assemblies, con- sensus decision-making. The women's movement, comments Phillips, took participation 'almost as its definition of democracy'. Thus there is a tradition of participatory democracy wrich exists within feminism, a tradition to which we can appeal in the current attempts to theorize a democracy based upon active citizenship.

Thus our ambition should be to reconceive and reconstruct the existing division between public and private spheres of life, conscious of the implications this will have for women's political participation, not in the expectation that this participation will remain distinct in form but in the hope that it will become more integral to a newly revitalized political arena.

The writing of Phillips and the above-mentioned contributors to the Mouffe collection add significantly to this debate on democratization and are invaluable reading for all who wish to ponder how we, as feminists, might engage with it.

\section{Judith Squires}

\section{Destabilizing Theory: Contemporary Feminist Debates}

\section{Edited by Michèle Barrett and} Anne Phillips

Polity Press: Cambridge, 1992

ISBN 0745607940 , £11.95 Pbk

ISBN $0745607942, £ 45.00 \mathrm{Hbk}$

What a feast: a specially commissioned collection of papers, all new bar one, and that one revised, from feminists working in Britain, Australia and the United States reflecting on similar questions from their own disciplinary locations in the humanities and social sciences. As readers of this journal know, unitary conceptions of feminist theory or feminist interests have been blown apart by the politics of difference and by all those trends that are subsumed under the rather ambiguous label of postmodernism. Indeed some of the key debates of the last two decades that have led to the current instability have been in this very journal.

One of the aims of this collection is to reflect on the gulf that now seems to yawn between the feminist theory of the 1970s and the theories of the 1990s. Reading the editors' introduction is a salutary reminder of how the language of feminism - as well as the politics - has changed over these two decades. Questions of meaning, identity, representation, difference, are now the subject of debate rather than older preoccupations about social structures, production and reproduction, domestic labour and so on. Is bridging the gap 
between these languages, between the different political projects of the 1970 s and 1990s possible? Is it even a desirable aim? Should we see the changed agenda of feminism as an advance on earlier debates, or as a distraction from our earlier certainties about our aims and political agenda? Does the focus on difference and heterogeneity deflect attention from systematic and structured inequalities? In posing these and other questions Destabilizing Theory is a valuable contribution to the growing literature about the possibility of a specifically feminist epistemology. Have we anything general left to say?

These are vexed and challenging questions and the contributors to this exciting collection have a range of opinions about not only possible answers but also the validity of the questions themselves. The breadth and depth of scholarship that is employed in getting to grips with them is inspiring and exciting - a clear indication of the ways in which feminist scholarship has come of age in the last twenty years. And, indeed, the serious academic positions and honours of the scholars who have contributed to this collection are a further indication of feminist entrenchment in the academy to a degree that would have seemed almost unthinkable two decades ago. However, only Chandra Talpade Mohanty, among the contributors, directly raises the question of the implications of her own/other feminists' location in particular institutional structures before she turns to the political implications of the coincidence of interest among feminist and anti-racist/Third World postcolonial studies in questions of difference and political commonalities.

The editors each contributed a chapter - one at the beginning and one at the end. Anne Phillips, whose paper is the first substantive chapter, contributes a polished and nowfamiliar critique of the universal, masculinist assumptions embedded in conventional liberal political theory. Michele Barrett closes the book with a careful reflective piece on the cultural, 'deconstructive' turn in feminist theorizing. Barrett's final chapter is preceded by a paper by Gayatri Chakravorty Spivak in which she also addresses questions about language and meaning in an uncharacteristically accessible essay about the politics of location between cultures which is partly based on a conversation with Barrett. This chapter stimulated me to return to Spivak's earlier work which I find difficult to understand.

The other contributors range widely across contemporary debates, from key issues in social and political theory (the chapters by Walby and by Pringle and Watson), through theories of sexual identity and the body (Martin and Gatens), to questions about meaning and representation in painting (Pollock) as well as in text. Sadly the editors did not provide a concluding 'pulling together' final chapter so the reader is left to sort out for herself where the authors agree and disagree but it is an absorbing task. It should not surprise those familiar with Sylvia Walby's growing body of work on patriarchy that she is perhaps the most wedded to the continued relevance of prepostmodern (or is post-postmodern as she hints in her title) theoretical structures, continuing an argument she has begun elsewhere about the transition between different forms of patriarchy. Her antagonism to discourse theory nicely sets the scene for other authors to disagree with her and this they do in a fascinating mélange of different styles and approaches. Coming immediately after Walby's measured academic style, the opening of the next chapter, in which Rosemary Pringle and Sophie Watson recount a dream one of them had, comes as quite a surprise. In an interesting paper, they go on to argue that postmodern or poststructuralist thought, more commonly discussed in the arena of cultural 
politics, may be relevant to the development of feminist approaches to the state.

But to single out particular chapters is invidious. All the contributions are interesting. Most of them are 'tasters' or summaries of more complex bodies of work published elsewhere in more detail. Gatens, for example, ranges widely in a few brief pages over theories of power, difference and the body, whereas Pollock manages both to distil and expand some of the arguments of her earlier collection, Visions of Difference, in a provocative essay that is nicely illustrated (thanks Polity for not bumping the price up by too much). The chapters hum with passion and excitement. Their authors display an enviable grasp of contemporary critical theory and yet, in the limited space allocated to them, they manage to deal with complex issues about discourse, language and representation in a clear, succinct and relatively accessible way. This collection should thus play an important part in introducing these debates to the uninitiated, the sceptical and those without much time! Hopefully, however, everybody who reads these short chapters will be persuaded to turn to other sources that explore similar issues in more detail.

If I had a quibble with the overall emphasis of the collection, however, it would be that the sheer intellectual thrills of the book tend to outweigh discussion of the political implications of contemporary theoretical destabilization. This is not to deny, of course, the political significance of the deconstruction and reconstruction of knowledge but rather to ask for clearer views about the ways in which we might build on our commonalities as well as try to understand our differences: ways in which we might move towards what Mohanty calls here 'engagement rather than discovery'. But perhaps this might be the subject of a second collection: hopefully as stimulating as this first one.

\section{Linda McDowell}

